\title{
Propriedades Antivirais de Fulerenos Funcionalizados com Tiofeno
}

Os fulerenos têm sido amplamente utilizados como scaffolds versáteis na preparação de materiais funcionais avançados e na síntese de compostos com propriedades biológicas promissoras. A funcionalização covalente de fulerenos é considerada a forma mais eficiente de obtenção de derivados com propriedades interessantes. No entanto, esta funcionalização pode originar um grande número de isómeros quando estão envolvidos vários grupos funcionais, pelo que são muito úteis abordagens seletivas para a introdução de substituintes.

Olga A. Kraevaya (Institute for Problems of Chemical Physics da Academia Russa de Ciências, Chernogolovka, Rússia) e colegas desenvolveram uma reação que converte derivados de fulereno do tipo $\mathrm{C}_{60} \mathrm{Ar}_{5} \mathrm{Cl}$ em fulerenos com unidades tiofeno do tipo $\mathrm{C}_{60} \mathrm{Ar}_{5}$ (tiofeno) (na imagem). A equipa de investigaç̧ão iniciou o estudo a partir de um conjunto de precursores $\mathrm{C}_{60} \mathrm{Ar}{ }_{5} \mathrm{Cl}\left(\mathrm{Ar}=\mathrm{C}_{6} \mathrm{H}_{5}\right.$ ou $\left.p-\mathrm{C}_{6} \mathrm{H}_{4}\left(\mathrm{CH}_{2}\right)_{n} \mathrm{CO}_{2} \mathrm{Mecom} \mathrm{n}=1,2,3\right)$, que reagiram com diversos tiofenos substituídos, na presença de $\mathrm{SnCl}_{4}$, água e 1,2-diclorobenzeno a $80^{\circ} \mathrm{C}$.

Os fulerenos funcionalizados com grupos tiofeno foram obtidos com rendimentos de $40-85 \%$. A introdução de grupos éster permite uma hidrólise posterior originando ácidos policarboxílicos baseados em fulerenos solúveis em água. A atividade biológica foi avaliada, tendo evidenciado uma atividade antiviral promissora contra os vírus da imunodeficiência humana (HIV) e da gripe.

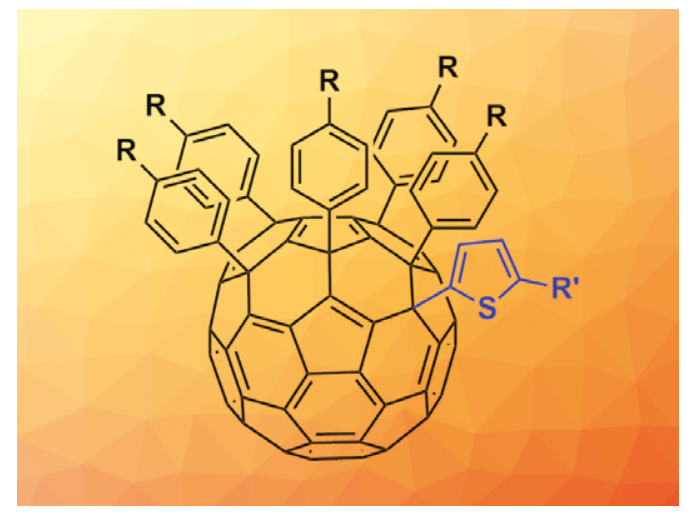

Crédito: ChemistryViews

$$
>
$$

\section{Ana Paula Esteves}

aesteves@quimica.uminho.pt

\section{Fontes}

Thiophene-Functionalized Fullerenes with Antiviral Properties, chemistryviews.org/ details/news/11317130/Thiophene-Functionalized_Fullerenes_with_Antiviral_ Properties.html (acedido em 04/09/2021).

O. A. Kraevaya, V. S. Bolshakova, A. S. Peregudov, A. V. Chernyak, N. A. Slesarenko, V. Y. Markov, N. S. Lukonina, V. M. Martynenko, E. O. Sinegubova, A. F. Shestakov, V. V. Zarubaev, D. Schols, P. A. Troshin, Org. Lett. 2021, 23, 7226-7230. DOI: 10.1021/ acs.orglett.1c02623.

\section{Fugas em Sistemas de Esgotos Podem Libertar Fármacos em Rios}

Os fármacos são um grrupo de contaminantes ambientais encontrados com frequência em águas naturais como resultado do descarte através de sistemas de esgotos. As concentrações de compostos farmacologicamente ativos são geralmente usadas para determinar o seu impacto em organismos que vivem em riachos e em rios. No entanto, essas concentrações podem mudar rapidamente e amostras obtidas em determinados instantes não refletem de modo correto os efeitos cumulativos de fármacos na vida aquática. Em vez disso, a quantidade de um poluente que passa por um riacho ou rio ao longo do tempo representa melhor os riscos para ambientes a jusante.

Megan L. Fork (Instituto Cary de Estudos de Ecossis- temas, Millbrook, EUA) e colegas estudaram a quantidade de medicamentos transportados por um riacho urbano em Baltimore. A equipa testou a água de um riacho que escoa para o Baltimore's Inner Harbor, em Maryland, EUA. Para isso, usaram cromatografia líquida acoplada a espectrometria de massa (LC-MS) para analisar amostras semanais recolhidas durante um ano. Os investigadores verificaram que quantidades substanciais de alguns fármacos eram transportadas pela corrente ao longo do ano apesar das concentrações serem, geralmente, baixas. Nos estudos realizados, encontraram 16 fármacos diferentes, cuja presença e concentrações variavam consideravelmente de semana para semana. 0 antibiótico 